\title{
A comparison of the effects of estrus cow serum and fetal calf serum on in vitro nuclear maturation of bovine oocytes
}

\author{
J Spiropoulos, SE Long \\ University of Bristol, School of Veterinary Science, \\ Department of Animal Husbandry, Langford House, Bristol BS18 7DU, UK
}

(Proceedings of the 9th European Colloquium on Cytogenetics of Domestic Animals; Toulouse-Auzeville, 10-13 July 1990)

cattle / female meiosis / in vitro maturation / oocyte

\section{INTRODUCTION}

The use of in vitro matured (IVM) oocytes in in vitro fertilization (IVF) programs requires an exact knowledge of the timing of nuclear maturation events. In cattle, the timing of IVM prior to IVF has been variously reported to be 19-22 h (Goto et al, 1988) up to $27 \mathrm{~h}$ ( $\mathrm{Xu}$ et al, 1987). Correct IVM is necessary to avoid fertilization of premature or aging oocytes. In IVF programs the criteria used for oocyte maturation are cumulus cell expansion and extrusion of the first polar body. Neither are direct assessments of cytoplasm maturation, which is one of the most important factors for successful IVF, but since fertilization in vivo occurs when the oocyte is at metaphase II (MII) it is usually assumed that completion of meiosis is accompanied by acquisition of developmental competence by the oocyte. Thus, in vitro, it is also assumed that complete oocyte maturation is acheived by the MII nuclear stage.

In this study the timing of the meiotic process during IVM of oocytes is examined under conditions similar to those used for IVF programs.

\section{MATERIALS AND METHODS}

Ovaries were collected from adult cows and heifers approximately 20 min after slaughter and transported to the laboratory in sterile phosphate-buffered saline (PBS) or normal saline supplemented with $100 \mathrm{IU} / \mathrm{ml}$ penicillin and $100 \mu \mathrm{g} / \mathrm{ml}$ streptomycin at between $30-38^{\circ} \mathrm{C}$. Ova were collected from follicles $1-6 \mathrm{~mm}$ in diameter by aspiration with an 18 gauge needle within $2-3 \mathrm{~h}$ of the animal's death. The cumulus-oocyte complexes (COC) were washed twice in TCM-199 with Hepes containing $20 \%$ fetal calf serum (FCS) and $50 \mu \mathrm{g} / \mathrm{ml}$ gentamicin and then 
transferred into the culture medium. The culture medium was TCM-199 with $2.2 \mathrm{~g} / \mathrm{l}$ sodium bicarbonate plus $50 \mu \mathrm{g} / \mathrm{ml}$ gentamicin supplemented with either $20 \%$ FCS or $20 \%$ estrus cow serum (ECS). A total of 479 oocytes were cultured, 320 with added granulosa cells and 159 without.

Oocyte culture was either in droplets of medium under sterile paraffin oil in a Petri dish or in multiwell plates under paraffin oil, and in $5 \% \mathrm{CO}_{2}$ in air at $39^{\circ} \mathrm{C}$ for between 8 and $25 \mathrm{~h}$.

To harvest, the cumulus cells were removed either by putting the $\mathrm{COC}$ in a $0.1 \%$ hyaluronidase:PBS solution for $2-10 \mathrm{~min}$ and flushing through a fine pipette or by a quick spin with a whirlimixer. Chromosome preparations were made from the denuded oocytes using either Tarkowski's method (1966) or a modification of the method of Dyban (1983). The modification consisted of placing the oocyte in Tyrode's acid ( $\mathrm{pH} 2.5$ ) for a few seconds after the hypotonic treatment. This softens the zona pellucida. Next the oocyte is placed in fixative (3:1, acetic acid-methanol) for 1-2 min and then transferred to a wet, ice-cold slide. The fixative is allowed to evaporate and the slides to dry in air. Staining was with a $10 \%$ solution of Giemsa at $\mathrm{pH} 6.8-7.0$

The ECS was obtained by collecting blood from cows as soon as possible after behavioral estrus was first noted. The serum was inactived by heating at $56^{\circ} \mathrm{C}$ for $30 \mathrm{~min}$ before use.

\section{RESULTS}

Cumulus-oocyte complexes with added cumulus cells achieved better and more extensive cumulus cell expansion than those without added cells, but this was not correlated with the stage of meiotic division after a given culture time or the quality of the chromosome preparations.

Denuding the oocytes by fine pipetting was much better than the use of the whirlimixer because many oocytes were lost using the latter technique, presumably by sticking to the wall of the tube.

The modified Dyban's method for chromosome preparations (Dyban, 1983) was preferred to that of Tarkowski (1966) because the spreading was more controllable and there was less chance of losing chromosomes, thus making assessment of chromosomal abnormalities more reliable.

The meiotic stage of oocytes after different culture times are shown in table I.

Table I. Comparison of the effects of culture supplementation with fetal calf serum (FCS) or estrus cow serum (ECS) on bovine oocyte maturation time in vitro.

\begin{tabular}{llrlllll}
\hline $\begin{array}{l}\text { Culture } \\
\text { time }(h)\end{array}$ & Serum & $\begin{array}{c}\text { No of } \\
\text { oocytes }\end{array}$ & Diplotene & Diakinesis & MII & $\begin{array}{c}\text { Undiagnosed } \\
\text { chromosomes }\end{array}$ & $\begin{array}{c}\text { Ooplasm but } \\
\text { no chroms }\end{array}$ \\
\hline $8-12$ & FCS & 73 & $9(12.3)^{\mathrm{a}}$ & $37(50.7)$ & $6(8.2)$ & $8(11)$ & $13(17.8)$ \\
$8.5-12.5$ & ECS & 100 & 1 & 62 & 1 & 23 & 13 \\
$19-25$ & FCS & 260 & $1(0.4)$ & $14(5.4)$ & $207(79.6)$ & $13(5)$ & $25(9.6)$ \\
$22.5-23.5$ & ECS & 46 & 0 & $4(8.7)$ & $49(87.0)$ & $2(4.4)$ & 0 \\
\hline
\end{tabular}

a Percentages are given between parentheses. 
There was no statistical difference between the percentage of oocytes at diakinesis (fig 1) after $8-12$ h of culture $\left(\chi^{2}=1.76 ; P=0.1\right)$ or at metaphase II (fig 2) after $19-25$ h of culture $\left(\chi^{2}=0.74 ; P=0.1\right)$ with FCS or ECS.

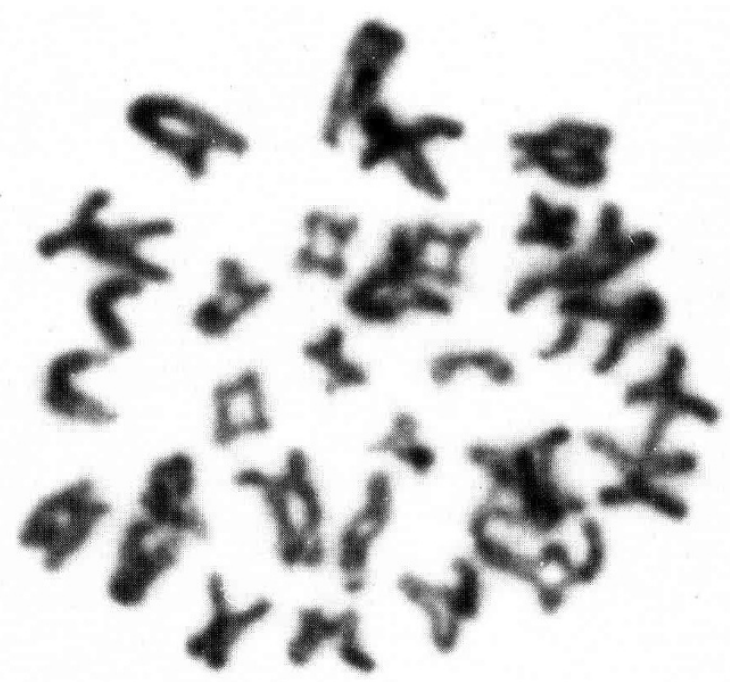

Fig 1. Chromosomes from a bovine oocyte at diakinesis after in vitro culture for approximately $10 \mathrm{~h}$.

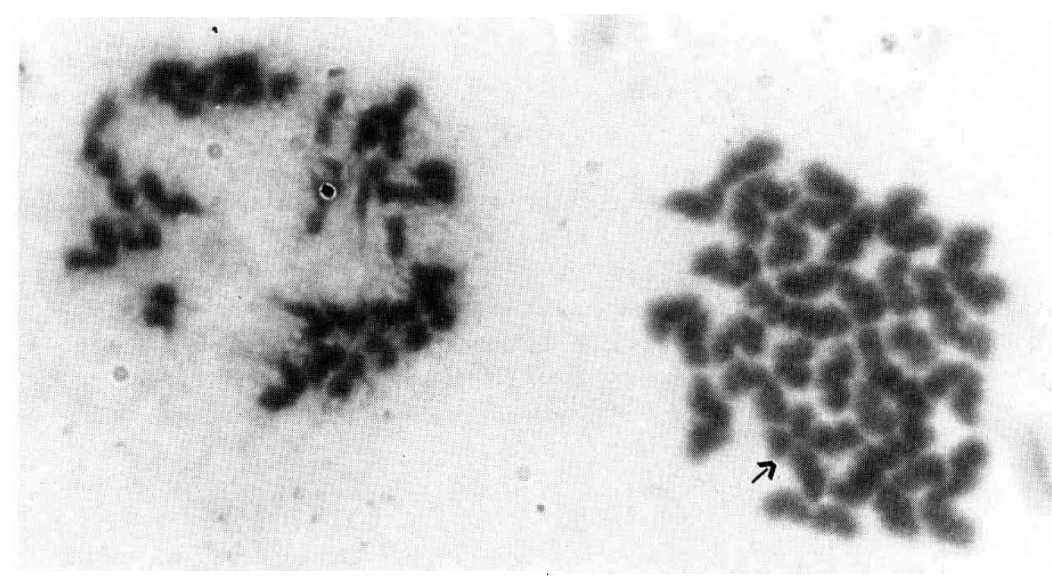

Fig 2. Chromosomes from a bovine oocyte at the second metaphase after in vitro culture for approximately $22 \mathrm{~h}$. The arrow indicates the $\mathrm{X}$ chromosome. On the left is the degenerating chromatin of the first polar body. 


\section{DISCUSSION}

An interesting finding in the present study was that the extent of the expansion of the cumulus cells was not found to correlate with the stage of nuclear maturation. Therefore, it would seem unwise to use this phenomenon as a criterion of IVM for IVF.

No difference was found in nuclear maturation time using the two different sources of serum supplementation. Lu et al (1987) reported higher IVF rates when ECS was used as the supplement. Therefore, it may be that the ECS contributes to cytoplasmic maturation.

The results from the present study of timing of nuclear maturation are in broad agreement with those previously reported. Sus et al (1988) found that $62 \%$ of bovine COCs in serum-free TCM-199 progressed to diakinesis after 8.25-12.5 h of culture and $72 \%$ reached MII after $19.5-25.75 \mathrm{~h}$ of culture. Similar percentages reached MII after 24-27 h of culture in TCM-199 supplemented with $15 \%$ FCS (61.8\%) (Leibfried and First, 1979) or when supplemented with $20 \mathrm{mg} / \mathrm{ml}$ of bovine serum growth protein $(71.4 \%$ ) (Liehman et al, 1986). A somewhat longer maturation time of $30 \mathrm{~h}$ was reported by $\mathrm{Xu}$ et al (1986) when they cultured COCs in Ham's F12 with $20 \%$ FCS.

In vivo, the oocyte resumes meiosis after the luteinizing hormone (LH) peak and, in cattle, reaches MI after 8-19 h and MII after 20.5-25 h (Kruip et al, 1983). Therefore, in vitro maturation times are very similar to those occurring in vivo. It seems likely, therefore, that, once the oocyte resumes meiosis, progress to MII is spontaneous and at a fixed rate. In vivo, ovulation takes place $24-30 \mathrm{~h}$ after the LH peak (Hopkins, 1989), that is, some time after the oocyte will have achieved nuclear maturation. It is possible that this extra time allows for the completion of cytoplasmic maturation.

\section{REFERENCES}

Dyban AP (1983) An improved method for chromosome preparations from preimplantation mammalian embryos, oocytes or isolated blastomeres. Stain Technol 58, 69-72

Goto K, Kajihara Y, Kosaka S, Koda M, Nakanishi Y, Ogawa K (1988) Pregnancies after co-culture of cumulus cells with bovine embryos derived from in vitro matured follicular oocytes. J Reprod Fertil 83, 753-758

Hopkins SM (1989) Reproductive patterns of cattle. In: Veterinary Endocrinology and Reproduction. (McDonald LE, ed) Lea and Febiger

Kruip TAM, Cran DG, van Beneden TH, Dieleman SJ (1983) Structural changes in bovine oocytes during final maturation in vivo. Gamete Res 8, 29-47

Leibfried L, First NL (1979) Characterisation of bovine follicular oocytes and their ability to mature in vitro. J Anim Sci 48, 76-87

Liehman P, Greve T, Xu KP (1986) Nuclear and cytoplasmic maturation of bovine oocytes cultured with dbc AMP, FSH and hCG. Acta Vet Scand 27, 566-574

Lu KH, Gordon I, Gallagher M, McGovern H (1987) Pregnancy established in cattle by transfer of embryos derived from in vitro fertilisation of oocytes matured in vitro. Vet Rec $121,259-260$

Sus U, Wuthrich K, Stranzinger G (1988) Chromosome configurations and time sequence of the first meiotic division of bovine oocytes matured in vitro. Biol Reprod 38, 871-880 
Tarkowski AK (1966) An air-drying method for chromosome preparations from mouse eggs. Cytogenetics 5, 394-400

Xu KP, Greve T, Smith S, Hyttel P (1986) Chronological changes of bovine folicular oocyte maturation in vitro. Acta Vet Scand 27, 505-519

Xu KP, Greve T, Callesen H, Hyttel P (1987) Pregnancy resulting from cattle oocytes matured and fertilised in vitro. J Reprod Fertil 81, 501-504 